\title{
O PROCESSO DE INTERNACIONALIZAÇÃO DA METALÚRGICA DELTA: ANÁLISE BASEẢDA NO TRIPÉ DA ESTRATÉGIA
}

Data de submissão: 20/05/2014 Aceite: 20/04/2016

Ana Karine Lima de Medeiros ${ }^{1}$ Jane Costa de Menezes ${ }^{2}$ José Milton de Sousa Filho ${ }^{3}$ Mário Henrique Ogasavara ${ }^{4}$

\section{RESUMO}

Este artigo, de natureza teórico-empírica, visa analisar o processo adotado por uma empresa do ramo metalúrgico e gráfico no tocante à sua estratégia de internacionalização. Para tanto, foi realizado um estudo de caso, com abordagem qualitativa, fundamentada no tripé estratégico de Peng (2009), mercado, resource-based view - RBV e instituição. Os principais objetivos deste trabalho consistem em investigar como se deu o processo de internacionalização da empresa objeto deste estudo, com base no tripé de Peng, e em identificar que fatores impactaram nos resultados obtidos na empreitada. A análise aponta que, a priori, as decisões tomadas pela empresa não foram pautadas em todos os aspectos necessários à adoção de um processo de internacionalização e que não houve ganhos operacionais, financeiros e econômicos na estratégia adotada.

Palavras-chave: Internacionalização. Empreendedorismo. Insucesso de estratégias.

\footnotetext{
1 Graduação em Administração pela Universidade Estadual do Ceará, UECE, graduação em Ciências Contábeis pela Universidade de Fortaleza, UNIFOR, mestrado em Administração de Empresas pela UNIFOR e doutorado em andamento em Administração de Empresas pela UNIFOR. Fortaleza - CE - Brasil. E-mail: anaklmedeiros@terra.com.br

2 Graduação em Comércio Exterior pela Universidade de Fortaleza, UNIFOR, mestrado em Administração de Empresas pela UNIFOR e doutorado em andamento em Administração de Empresas pela UNIFOR. Fortaleza - CE - Brasil. E-mail: jane_menezes@hotmail.com 3 Professor Titular do Programa de Mestrado e Doutorado em Administração de

Empresas da UNIFOR - CE (PPGA/UNIFOR). Graduação em Administração de Empresas pela Universidade Federal do Ceará, UFC, mestrado em Administração pela Universidade Federal de Pernambuco, UFPE e doutorado em Administração de Empresas pela Fundação Getúlio Vargas - SP, FGV-SP. Fortaleza - CE - Brasil. E-mail: miltonsousa@gmail.com

4 Professor Titular do Programa de Mestrado e Doutorado em Gestão Internacional da ESPM São Paulo (PMDGI/ESPM). Graduação em Administração de Empresas pela Universidade Estadual de Londrina (UEL). Master of Business Administration e Ph.D. in Management pela University of Tsukuba, Japão. Pós-doutorado pela National University of Singapore, Departamento de Estudos Japoneses. São Paulo - SP - Brazil. E-mail: mario.ogasavara@espm.br
} 


\section{INTRODUÇÃO}

Durante décadas, as empresas dos países emergentes como o Brasil foram vistas essencialmente como exportadoras. Segundo Xavier e Turolla (2006), o processo de internacionalização das empresas brasileiras, através do investimento direto no exterior, ainda é muito rudimentar e, por isto, pouco estudado.

A internacionalização é considerada uma das estratégias que as empresas podem adotar para obter vantagens competitivas e fazer frente a seus concorrentes dentro do mercado nacional e internacional. No entanto, não há de se falar em alguma estratégia corporativa sem que isso seja precedido de um planejamento adequado para avaliação de todos os cenários, opções e riscos de cada escolha, bem como da capacidade de implementação das ações planejadas (VASCONCELLOS, 2008). Essas são questões chaves, pois nem toda estratégia adotada pelas empresas é capaz de torná-las mais lucrativas ou melhores em algum determinado aspecto. Segundo Hoskisson et al (2009, p. 5), ainda mais comum do que as empresas que fracassam completamente são aquelas que deixam de ser competitivas devido a uma inaptidão em realizar as mudanças necessárias para o sucesso contínuo.

Nesta pesquisa, optou-se por estudar o processo de internacionalização de uma empresa do ramo metalgráfico. Esta escolha está pautada em duas razões: (i) o processo de internacionalização ter ocorrido recentemente no ano de 2004, e (ii) em menos de dois anos a sucursal estrangeira da empresa encerrou suas atividades. $O$ presente estudo objetiva responder: Em qual contexto se deu a internacionalização da Metalúrgica Delta? E que fatores levaram a empresa a não obter êxito nesta estratégia? Esta pesquisa visa contribuir no entendimento, por meio de um estudo real e prático, das possíveis motivações que acarretam no insucesso de uma estratégia de internacionalização, buscando, assim, avançar nas reflexões teóricas, metodológicas e/ou práticas já disponíveis neste campo de estudo.

Os objetivos específicos da pesquisa são: (i) investigar como se deu o processo de internacionalização da empresa Metalúrgica Delta, amparado na visão mercado x RBV x instituição; e (ii) Descrever que fatores mpactaram no insucesso da empreitada. $O$ tema de internacionalização de empresas mostra sua relevância na medida em que aborda a experiência de uma empresa que, num processo de internacionalização, teve que retroceder devido ao insucesso da estratégia adotada. Além disso, pode-se destacar a importância do tema, dados os poucos estudos práticos sobre motivações reais do insucesso de estratégias de internacionalização.

O presente trabalho, além desta introdução, está dividido em quatro seções. A primeira trata das principais vertentes teóricas que explicam quais os motivos que levam as empresas a se internacionalizarem. A segunda explicita a metodologia utilizada no trabalho, bem como o método de coleta e de análise de dados. A terceira seção trata do estudo de caso em si, e, na última, são feitas as considerações finais, sendo retomadas as principais lições obtidas do caso estudado.

\section{INTERNACIONALIZAÇÃO DE EMPRESAS}

\subsection{Internacionalização como Estratégia Competitiva}

No campo da internacionalização, as pesquisas têm mostrado que diferentes teorias e fatores são importantes nas fases precoces e tardias do desenvolvimento internacional de empresas (JOHANSON; VAHLNE, 2009). Distintos modelos e teorias foram desenvolvidos para aumentar a compreensão da expansão internacional das organizações, tais como Custo de Transação (HENNART, 1988; WILLIAMSON; 2005); Teoria da Internalização (BUCKLEY; CASSON, 2009); Modelo de Uppsala (JOHANSON; VAHLNE, 2009), Paradigma Eclético (DUNNIG; LUNDAN, 2008); e Born Global (SHARMA; BLOMSTERMO, 2003). 
Recentemente, Peng (2009) apresentou o modelo "Tripé Estratégico", que resume em três grandes dimensões ou perspectivas o modo de explicar a estratégia de uma organização: (i) os recursos e as capacidades da organização, (ii) o ambiente de competição da indústria na qual a empresa está inserida e (iii) as variáveis relacionadas ao ambiente institucional. Segundo o autor, esses três fatores influenciam diretamente na estratégia, os quais impactam o desempenho da empresa.

\subsubsection{Visão Baseada em Recursos e Capacidades da Firma}

De acordo com Johanson e Wiedersheim-Paul (1975), as principais barreiras para a internacionalização de uma empresa são a falta de conhecimento e a de recursos. A visão baseada em recursos (Resource Based View of the Firm - RBV) entende que as empresas que têm capacidades e recursos específicos poderão ser distintas de outras organizações. Mas, para cumprir seu papel distintivo, estas capacidades e recursos devem ser valiosos, raros, inimitáveis, e essas características seriam as causas das diferenças na rentabilidade das organizações (BARNEY, 1991; BARNEY; HESTERLY, 2011).

Barney (1991) define os recursos como ativos, capacidades, processos organizacionais, atributos da firma, informação, conhecimento, que são controlados pela empresa e que lhe permitem compreender e colocar em ação as estratégias capazes de incrementar sua eficácia e eficiência. Com essa definição, pode-se listar uma série de mecanismos, das mais variadas naturezas, como um talento gerencial exclusivo: a cultura organizacional, as competências distintivas ou idiossincráticas em geral, que sejam de difícil replicação (SOUSA FILHO; BARBIERI, 2015). Por sua vez, Peng (2009) afirma que os recursos podem ser tangíveis ou intangíveis. Os recursos tangíveis, por exemplo, são os recursos financeiros, a infraestrutura tecnológica e o organizacional físico; enquanto os ativos intangíveis são os recursos humanos, a inovação, a reputação, dentre outros.

Prange e Vendier (2011) afirmam que, ao expandir suas atividades internacionalmente, as empresas acumulam capacidades, como aprendizagem, adaptação cultural e receptividade à mudança. Slack, Chambers e Johnston (2009) destacam que nenhuma empresa pode simplesmente escolher em que parte do mercado irá atuar sem levar em conta as restrições impostas por suas operações, bem como as suas competências.

Por fim, Helfat et al (2007) afirmam que o benefício que as empresas podem obter por meio das capacidades dinâmicas depende não apenas dos recursos e da capacidade de gestão, mas também do contexto em que as capacidades estão sendo operadas. Portanto faz-se necessário compreender o ambiente no qual as empresas estão inseridas. A seguir, será discutido o segundo pilar do tripé estratégico.

\subsubsection{Visão Baseada em Mercado}

A linha estratégica que orienta os determinantes da indústria discutidos por Peng (2009) foi apresentado por Porter (1980) e é composta por fatores como a competitividade entre as empresas, as barreiras para novos entrantes, fornecedores e compradores com poder de negociação e de produtos/ serviços substitutos. Do ponto de vista de Porter (1986), através do conhecimento de pressões competitivas, observam-se os pontos fortes e críticos da companhia. Por sua vez, estes apontam as áreas em que mudanças estratégicas podem resultar no retorno máximo e põem em destaque as áreas em que as tendências da indústria são da maior importância, quer como oportunidade, quer como ameaças.

Destacando a atuação dos fornecedores, Porter (1999) afirma que estes têm capacidade de ameaçar o desempenho das empresas de uma indústria através da elevação dos preços ou da redução da qualidade dos bens e serviços. Assim, os fornecedores poderosos dispõem de condições para espremer a rentabilidade de um setor que não consiga compensar os aumentos de custos nos próprios preços. 
No ângulo dos clientes, Porter (1999) enfatiza que estes também possuem poder de negociação, pois são capazes de forçar a baixa dos preços, de exigir melhor qualidade ou de cobrar mais prestação de serviços, jogando os concorrentes (fornecedores) uns contra os outros em detrimento dos lucros do setor. O poder de negociação dos consumidores tende a ser maior quando existe concentração da indústria dos consumidores ou quando a importância da indústria consumidora for alta. A influência dos consumidores também pode ser alta quando estes consomem em grandes quantidades ou quando ameaçam promover uma integração para trás, em outras palavras, assumem atividades que geralmente são realizadas em momentos anteriores na cadeia produtiva (PORTER, 1999).

Referente às formas de proteção a novos entrantes, para Porter (1986), os novos entrantes em um setor trazem novas capacidades, desejo de ganhar participações no mercado e, em geral, recursos substanciais. Por outro lado, existem duas expectativas dos entrantes em relação às barreiras: a existência já consolidada de barreiras de entrada e a ameaça de reação dos competidores já estabelecidos (PORTER, 1986).

Já sobre a ameaça de produtos ou serviços substitutos, Porter (1999) afirma que, por imporem um teto aos preços, os serviços substitutos limitam o potencial de um setor, a menos que este consiga melhorar a qualidade do produto ou, de alguma forma (através de marketing, por exemplo), estabelecer uma diferenciação - assim sofrerá as consequências nos lucros e, possivelmente, no crescimento.

Nesse contexto, implantar uma estratégia é fazer escolhas, definir como sua empresa vai se destacar. Essas escolhas representam os caminhos eleitos pela empresa para alcançar vantagem competitiva (PORTER, 1990). No entanto, a estrutura da indústria é modificada de acordo com os padrões do país. Quanto maior o dinamismo do ambiente competitivo, maior a possibilidade de uma subsidiária desenvolver uma estratégia sustentável de ação nesse mercado (BIRKINSHAW; FRY, 1998).

Desta forma, para compreender os efeitos do fator indústria, que determina o comportamento das multinacionais, vamos considerar as cinco forças de Porter (1980), que dirigem a concorrência na indústria descrita em seu quadro de diamante, conforme mostra a Figura 1.

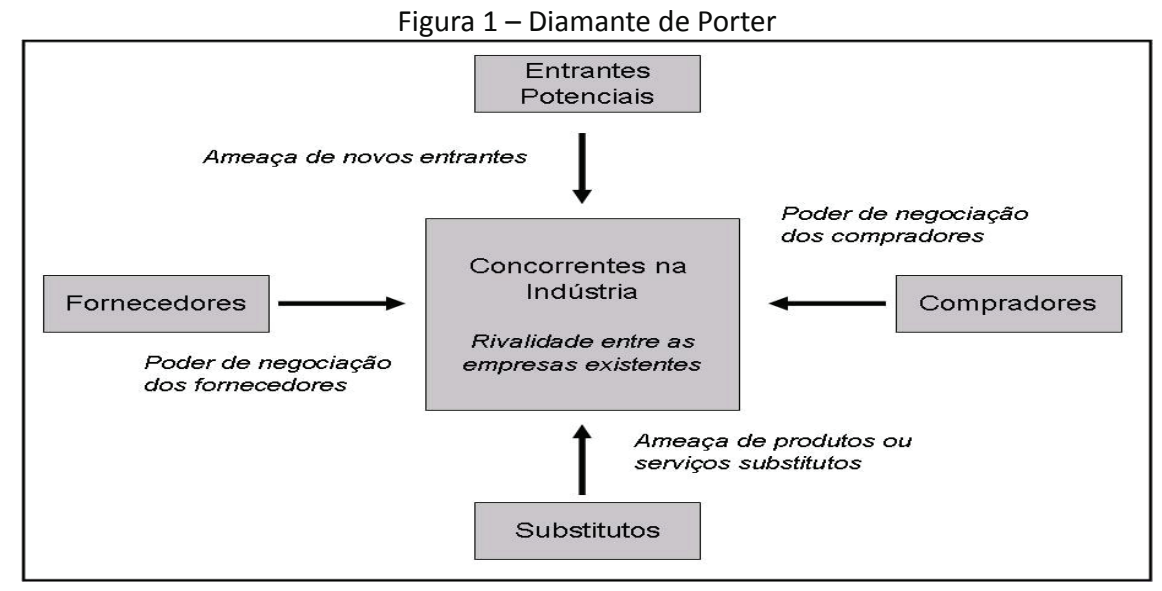

Fonte: Porter (1990)

\subsubsection{Visão Baseada em Instituição}

Nos últimos anos, as instituições são enfatizadas como uma nova variável que influencia as estratégias internacionais e a performance das empresas (PENG; WANG; JIANG, 2008; PENG, 2009). Segundo North (1990), as instituições são constrangimentos criados pelo homem que estruturam a interação humana. 
Perante esse panorama, assistem-se as tentativas para estabelecer uma teoria sobre o efeito institucional (FABRY; ZEGHNI, 2010). Kiss e Danis (2008) afirmam que as redes sociais dos empreendedores desempenham um papel importante na internacionalização das empresas.

Contudo, apesar da relevância adquirida pelas instituições, só nos estudos de Peng (2009) as instituições passam a ser consideradas em conjunto com os recursos específicos e com a estrutura da indústria, tendo como objetivo analisar a estratégia internacional das empresas. Neste quadro, a estrutura da indústria é essencial para indicar o ambiente competitivo em que a empresa concorre, enquanto os recursos qualificados que a empresa possui são necessários para responder ao ambiente em que está inserida, oferecendo à empresa a possibilidade de estabelecer vantagens competitivas (GALBREATH; GALVIN, 2008).

Uma das contribuições da visão baseada em instituições é a ênfase na importância das instituições, das culturas e da ética, como bases que impulsionam ou restringem as escolhas estratégicas (PENG; WANG; JIANG, 2008; PENG, 2009). Peng (2009) considera que o quadro institucional é constituído por instituições formais, que incluem leis, regulamentos e regras, sendo o pilar de sustentação dessas instituições a coerção.

Por outro lado, entre as instituições informais estão as normas, as culturas e a ética, sendo os dois pilares de sustentação destas instituições o normativo e o cognitivo. $O$ pilar normativo, pelo fato de estabelecer como as coisas devem ser feitas, refere-se a valores, a crenças e a normas que influenciam o comportamento das empresas. $O$ pilar cognitivo refere-se a valores e a crenças internalizados e convencionados (PENG; WANG; JIANG, 2008; PENG, 2009). Na tentativa de reduzir a incerteza econômica e os correspondentes custos de transação, os modelos institucionais ditam as regras do jogo de forma que os desvios sejam mitigados com facilidade (MONTICELLI; VASCONCELLOS; GARRIDO, 2017).

Essa visão sugere duas proposições: as escolhas estratégicas são feitas dentro de restrições institucionais; e, no caso de as instituições formais falharem, as instituições informais exercem o papel de reduzir a incerteza (PENG; WANG; JIANG, 2008; PENG, 2009).

Assim, com base no "modelo do tripé estratégico" de Peng (2009), consegue-se incorporar as três perspectivas (recursos, mercado e instituição), que o autor considera fundamentais na determinação da estratégia prosseguida por parte das empresas, conforme demonstra a Figura 2.

Figura 2 - Tripé estratégico

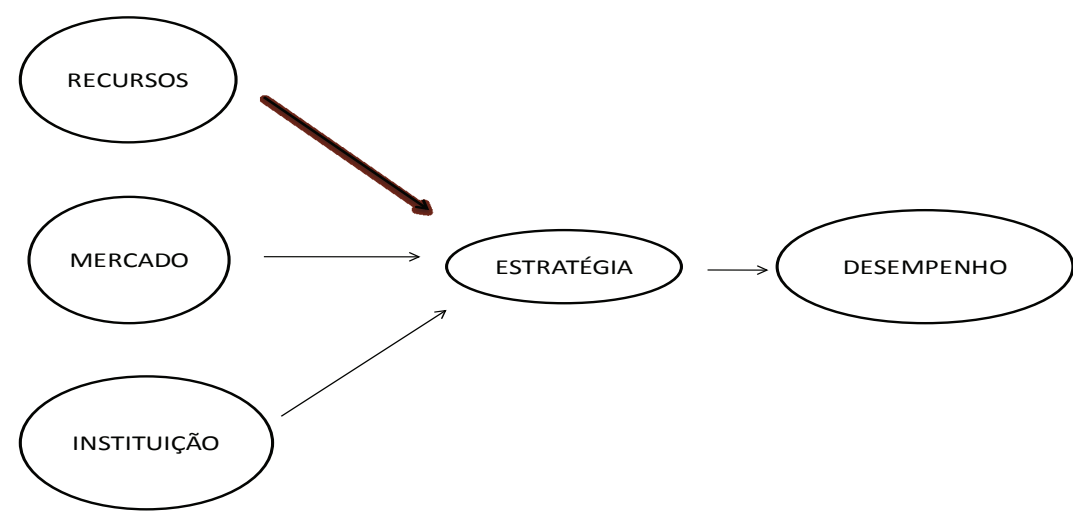

Fonte: Peng (2009) 


\subsection{Falhas no processo de internacionalização}

Independente da motivação, decidir internacionalizar é assumir um risco, dado que o processo está associado a incertezas, a complexidades, exigindo a disposição de diferentes tipos de recursos (CHEN; HSU; CHANG, 2013). Os riscos envolvidos e as restrições de recursos podem desencorajar os gestores avessos ao risco a realizarem a internacionalização. No meio acadêmico, ainda não existe consenso sobre o tema. Alguns alegam que os efeitos positivos e negativos do processo de internacionalização podem contrabalançar um ao outro (NUMMELA; SAARENKETO; LOANE, 2016). As estratégias adotadas são altamente dependentes do contexto (SLEUWAEGEN; ONKELINX, 2014), e as diferenças identificadas pelos pesquisadores podem ser devido ao ambiente/à localidade onde cada pesquisa foi desenvolvida.

O fato é que alguns processos de internacionalização não obtêm êxito e apresentam diversas falhas ao longo da sua tentativa de implementação. $O$ conceito de falha é fundamental para o campo do empreendedorismo (NUMMELA; SAARENKETO; LOANE, 2016) e, no contexto da presente pesquisa, refere-se a uma série de acontecimentos inesperados durante o processo de internacionalização que conduzem a um resultado indesejado, mas, ao mesmo tempo, pode ser considerada uma parte natural do ciclo de vida do risco (COAD, 2014).

Para Cardon, Stevens e Potter (2011), os fatores que desencadeiam a falha podem ser vistos como antecedentes à falha; além disso, a literatura existente indica fatores internos e externos como razões para o insucesso numa empreitada de internacionalização. Alguns autores ressaltam o papel dos administradores na implementação de estratégias empresariais. Segundo Nummela, Saarenketo e Loane (2016), a incompetência gerencial pode estar ligada à incapacidade dos administradores para lidar com as responsabilidades adicionais encontradas ao entrar em mercados internacionais. Nessa mesma linha, Ooghe e De Prijcker (2008) identificaram processos de falha incremental resultantes da incompetência gerencial, o que leva à queda dos lucros, às dificuldades de liquidez e, eventualmente, à falência. Por outro lado, conforme Carter e Wilton (2006), os empresários podem ser vítimas de circunstâncias oriundas de fatores externos, algumas vezes além de seu controle, como, por exemplo, situações de falhas de estratégias empresariais, nas quais instituições públicas e governamentais não criam condições macro-econômicas propícias ao desenvolvimento e crescimento internacional de empresas.

Embora algumas trajetórias de falha na internacionalização tenham sido descritas por outros pesquisadores, nenhum deles se estendeu além do processo para as consequências do fracasso, pois, não levaram em conta a estreita relação entre a falha em si e o próprio processo de internacionalização da empresa (NUMMELA; SAARENKETO; LOANE, 2016). Em complemento a esse raciocínio, Cardon, Steves e Potter (2011) mencionam que os resultados originados de falhas na internacionalização podem variar de produtivos para destrutivos. Nummela, Saarenketo e Loane (2016) acrescentam que existem ocasiões em que a falha pode não somente ser considerada necessária, mas também desejada, principalmente em processos em que a internacionalização resultou em empreendimento continuamente fraco em relação ao seu desempenho devido à incompetência da gestão, ao erro de cálculo, a expectativas excessivamente otimistas em relação ao ambiente macroeconômico da localidade ou à mudança de mercado. Estes autores finalizam mencionando que as consequências do fracasso em processos de internacionalização podem ser colocadas em um continuum de consequências, que vão desde a participação diminuída em atividades internacionais, ocasionando reestruturação e desinvestimento, até o completo encerramento do negócio.

Com o objetivo também de tentar contribuir no entendimento das falhas decorrentes de processos de internacionalização, Wang (2010) efetuou estudo de caso com base na experiência 
em uma das maiores players mudiais do comercio eletrônico, eBay, quando esta decidiu entrar no mercado chinês. Para o autor, uma série de fatores pode ser responsável pela falha de um empreedimento quando este envereda na estratégia de internacionalização. Wang (2010) menciona primeiramente que ter um negócio de sucesso em um mercado não significa automaticamente ter sucesso em outro usando os mesmos princípios e as mesmas estratégias. Logo após, o pesquisador enumera alguns fatores que podem ocasionar o insucesso em processos de internacionalização, sendo eles a falta de conhecimento do mercado de atuação, da concorrência, das leis locais e a ausência do drive de internacionalização na cultura da empresa.

No que se refere ao entendimento do mercado de atuação, Lu, Tao e Chan (2008) afirmam que a falta de compreensão aprofundada do ambiente de negócios e da dinâmica do mercado leva a empresa a gastar uma quantidade enorme de recursos, incluindo dinheiro, tempo e publicidade, no meio errado. Segundo Wang (2010), no caso da eBay, a empresa não observou que, na China, a maioria das pequenas empresas não usava a Internet, mas a televisão para divulgação de seus produtos. Por isso não adaptaram os seus produtos e serviços para que atendessem as necessidades do mercado chinês local, o que se tornou um dos problemas encontrados ao internacionalizar.

O segundo fator de insucesso citado por Wang (2010) foi a falta de conhecimento sobre os concorrentes da empresa que pretende se internacionalizar. Rein (2007), em concordância com Wang (2010), menciona que o não entendimento das estratégias dos competidores pode fragilizar a própria estratégia da empresa sobre como reagir às empreitadas dos players de mercado e facilitar a perda de consumidores, que se deslocam procurando atender as expectativas de consumo que têm.

O terceiro fator de insucesso, segundo Wang (2010), é o não conhecimento da legislação local. Em linha com esse fator mencionado por Wang (2010), para Carvalho (2013), um determinante importante na análise de um investimento estrangeiro são as instituições políticas e econômicas do país. A importância desse determinante é confirmada por sua alargada utilização na literatura empírica para explicar o fluxo de entrada de Investimento Direto Estrangeiro (IDE) num país. Seguindo o exemplo do caso da eBay, Ireland, Hoskisson e Hitt (2009) entendem que a não inclusão de serviços judiciais no seu sistema de venda, para garantir a credibilidade das operações, fez com que os consumidores chineses se sentissem desconfortáveis em relação à operação comercial e, isso, segundo Rein (2007), prejudicou a relação de confiança entre compradores e vendedores.

Por fim, Wang (2010) menciona a ausência do drive de internacionalização na cultura da empresa. A falta de uma consciência global ou internacional influencia a falta de planejamento e contribui para a permanência do desconhecimento dos processos internos necessários. $O$ autor complementa mencionando que os principais entraves envolvem desconhecer a taxa de câmbio, os custos portuários e aeroportuários, a burocracia alfandegária, os custos de frete internacional, os custos tributários e a diferenciação de ressarcimento de créditos de exportações, dentre outros.

Sintetizando o que os autores relataram, em outras palavras, o insucesso de uma empresa ao se internacionalizar é, em grande parte, devido à compreensão limitada do mercado local, a falta de adaptação e de personalização de seus serviços para o mercado local e a adoção de estratégia de gestão não compatível com o novo mercado. É diante de todo este contexto teórico que este estudo será desenvolvido.

\section{METODOLOGIA}

Este estudo tem o objetivo de tentar preencher algumas lacunas existentes na análise do contexto em que as empresas estão inseridas quando decidem se internacionalizar, bem como compreender as razões do insucesso de algumas empreitadas. No entanto, este é um tema 
muito amplo e, por isso, precisa ter sua delimitação em relação à abrangência, aos métodos e às técnicas a serem utilizados neste trabalho.

Esta pesquisa tem abordagem eminentemente qualitativa, que é comumente empregada em estudos descritivos e exploratórios (VIEIRA; ZOUAIN, 2006). O uso dessa abordagem justifica-se pelas vantagens de compreender a complexidade do fenômeno estudado e de todo o processo, aprofundando elementos que concorrem para o processo de internacionalização de empresas, bem como, os agentes causadores do insucesso destas estratégias.

Quanto à tipologia, esta pesquisa foi efetuada por meio de estudo de caso. Conforme Merriam (1998), o conhecimento produzido pelo estudo de caso é diferenciado, dado que é concreto, contextualizado e interpretativo. A técnica utilizada pode ser caracterizada como sendo particularista, pois trata de uma situação ou fenômeno particular, descritiva, uma vez que faz uma rica descrição do fenômeno, e heurística, pois tenta encontrar as razões do problema e suas soluções.

A coleta de dados deu-se por meio de entrevistas semiestruturadas, realizadas individualmente e gravadas em meio mecânico, com a permissão do entrevistado. A forma de obtenção dos dados se justifica pela melhor compreensão e compilação dos dados levantados, tanto por meio dos documentos, como também das observações.

As entrevistas foram realizadas com três participantes-chave do processo de internacionalização e ocorreram nos meses de outubro e novembro de 2013. Os entrevistados foram um dos proprietários e atual CEO da empresa estudada e um ex-CFO desta mesma empresa, porque eles conhecem a história da organização, os eventos marcantes, as estratégias e as pessoas que foram importantes para o processo. Foi entrevistado também o ex-controller que participou desse processo em conjunto com os fundadores. No presente trabalho, as entrevistas totalizaram seis horas e doze minutos de gravação, e todas foram transcritas na sua íntegra.

A coleta dos dados por meio de pesquisa documental utilizou dados secundários da própria organização, tais como: relatórios, informativos, livros e pesquisas institucionais. O tratamento de dados foi feito a partir da análise de conteúdo, aproximando-se da proposta de Bardin (2012), buscando, ao longo do trabalho, realizar a interpretação desses dados, relacionando com a perspectiva teórica adotada e com as outras informações coletadas nos documentos. A técnica justifica-se pela sua intenção principal, que é inferir conhecimentos relativos aos temas estudados, recorrendo a indicadores não necessariamente quantitativos.

\section{RESULTADOS}

A presente seção tratará dos resultados desta pesquisa. No item 4.1, será apresentada a caracterização da empresa. O item 4.2 tratará da análise do processo de internacionalização sob o prisma do Tripé de Peng. 0 item 4.3 discorrerá sobre as falhas do processo de internacionalização da Metalúrgica Delta e, por fim, o item 4.4 fará a discussão dos resultados encontrados à luz da literatura sobre o assunto.

\subsection{Caracterização da Empresa}

A empresa deste estudo é uma empresa familiar, fundada no estado do Ceará, nos anos 50. Os principais produtos fabricados pela empresa são latas destinadas ao envase de alimentos e de produtos químicos, bem como rolhas metálicas para o segmento de bebidas, sendo estas, seu carro-chefe. A área de atuação da empresa são as regiões Norte e Nordeste, e para fins de confidencialidade, ao longo desta seção, chamaremos a empresa em análise de Metalúrgica Delta.

Em 2001, o fundador da Metalúrgica Delta faleceu, e o cargo de liderança da empresa foi delegado a seu filho mais velho, que atualmente ainda permanece no cargo de CEO. 
O parque industrial da Metalúrgica Delta está instalado numa área de mais de 50 mil $\mathrm{m}^{2}$. A capacidade produtiva mensal de rolhas metálicas da empresa é, em média, de um bilhão de unidades. O processo produtivo dessas rolhas é composto por algumas etapas, sendo a mais importante a denominada de litografia ou estampagem. Nessa etapa, é feita a impressão de rótulos ou a "policromia das artes/rótulos" de cada uma das marcas contratantes. O controle de qualidade é feito de forma computadorizada, por meio de sensores de vídeo capazes de monitorar tanto a parte externa quanto a interna da rolha.

No segmento em que atua, a empresa tem apenas três concorrentes nacionais, localizados no Centro-Oeste, em Pernambuco e em São Paulo, sendo este último seu maior rival. Os principais clientes nacionais são empresas de bebidas de grande porte. Os mais representativos clientes estrangeiros são a Cervejaria Sab Miller, Danone Argentina, Quilmes e a Coca-Cola do Uruguai, a do Paraguai e a da Argentina.

A principal matéria-prima utilizada pela Metalúrgica Delta em seu processo produtivo é a folha de flandres, e seu maior fornecedor é a Companhia Siderúrgica Nacional - CSN, seguida por outros fornecedores chineses e coreanos, ainda não tão representativos nos negócios da empresa quando a análise desta pesquisa foi realizada.

\subsection{Análise da Internacionalização da Metalúrgica Delta baseada no tripé estratégico de Peng}

Até 2003, a estratégia adotada pela empresa era a de atender mercados internacionais por meio de exportação. No entanto, segundo o seu ex-CFO, para que a empresa pudesse sobreviver no mercado, havia duas opções: buscar mercados novos ou desenvolver novos produtos/ tecnologias. Com isso, a empresa decidiu que abriria uma sucursal estrangeira com o objetivo de acelerar seu processo de internacionalização. A referência de quando e onde abrir a sucursal está melhor detalhada na subseção 4.2.2.

Conforme mencionado na seção de metodologia, o fundamento da análise da internacionalização é o tripé estratégico de Peng (2009). A análise será iniciada com a visão baseada no mercado, seguida pela visão baseada nas instituições e pela visão baseada nos recursos internos da firma.

\subsubsection{Visão Baseada no Mercado}

A visão baseada no mercado fundamenta-se nas 05 (cinco) forças de Porter (1986). Esta foi a visão que pautou a decisão da empresa de abrir uma sucursal no exterior. Isto por que a própria Metalúrgica Delta avaliou de forma empírica os fatores de riscos de seu negócio. A seguir, será analisada cada uma das forças no contexto de internacionalização da empresa.

Sob o prisma dos fornecedores, a Companhia Siderúrgica Nacional - CSN é tida como estratégica, visto que possui grande relevância no negócio, pois detém o monopólio nacional de sua principal matéria-prima. Com a privatização da CSN em 1993, segundo o ex-CFO da Metalúrgica Delta, parte relevante da reestruturação da empresa foi pautada em metas de desempenho financeiro, e, com isso, o custo de aquisição da matéria prima elevou-se vertiginosamente, reduzindo a patamares críticos a rentabilidade da empresa.

$\mathrm{Na}$ análise do contexto dos clientes, em 1998 ocorreu a fusão da Antarctica com a Brahma e criação da AmBev. Antes da fusão, as empresas detinham $18 \%$ e $49 \%$ respectivamente do mercado brasileiro de cervejas, e, após a fusão, a nova empresa criada passou a deter $68 \%$ deste mesmo mercado (PREZZOTTO; LAVALL, 2010), ou seja, um mercado que já era concentrado ficou ainda mais. Com isso, o poder de barganha da AmBev ficou ainda maior e, por consequência, a 
Metalúrgica Delta foi se achatando entre a pressão por aumento do custo de matéria-prima, do lado da CSN, e a pressão por redução de preço da rolha metálica, por parte da AmBev.

Além desse fato, no ano de 2003, a empresa perdeu o fornecimento de rolhas para todas as franquias da Coca-Cola, e isso representava aproximadamente $20 \%$ de toda a sua produção mensal. Os entrevistados comentaram sobre a situação crítica da empresa em 2003. A perda de clientes tornou o parque fabril da Metalúrgica Delta ocioso em aproximadamente $50 \%$ naquele ano.

Na perspectiva de novos entrantes, a AmBev, em 2001, numa tendência de verticalizar seu negócio, criou uma empresa na Zona Franca de Manaus com o objetivo de produzir e suprir toda a necessidade de rolhas metálicas anteriormente compradas de terceiros. Com a criação dessa nova empresa, a Metalúrgica Delta não só perdeu seu maior cliente individual, bem como ficou com um elevado nível de ociosidade em seu parque fabril, entrando assim num processo contínuo de prejuízos, dados os altos custos fixo e financeiro. Segundo o atual CEO, a estratégia de verticalização da AmBev não só a fez se auto-suprir de um dos itens mais difíceis de gestão, visto ser uma commodities, mas também foi uma grande estratégia de redução de custos através de planejamento tributário.

No contexto pré-internacionalização, não foi mencionado por nenhum dos entrevistados o surgimento de produtos substitutos que pudessem ameaçar o mercado da Metalúrgica Delta.

No que se refere à visão dos concorrentes, da mesma forma que a Metalúrgica Delta, seus rivais sofreram os impactos da privatização da CSN e da criação de uma nova empresa da AmBev para produção de Rolhas Metálicas. Um de seus concorrentes, localizado na região central do Brasil, entrou com processo de recuperação judicial em 2010.

O concorrente localizado em São Paulo, tem forte atuação na região Sudeste. Fabrica praticamente os mesmos produtos que a Metalúrgica Delta, mas possui um diferencial: também produz tampas plásticas. $\mathrm{O}$ grupo econômico ao qual pertence também atua nos ramos de construção civil, incorporação imobiliária, financeiro e agropecuário. Deu um passo no sentido da internacionalização antes da Metalúrgica Delta. Em 1994 iniciou atividades através de uma sucursal, no Paraguai. Segundo o CEO da Metalúrgica Delta, concorrente localizado em São Paulo sofreu grande impacto pós criação da empresa de Rolha Metálicas da AmBev, mas, por ser bem consolidada na região Sudeste, nunca envidou esforços no sentido de buscar mercado na região dominada pela Metalúrgica Delta (Norte e Nordeste).

\subsubsection{Visão Baseada na Instituição}

Se a visão baseada no mercado nacional impulsionou a Metalúrgica Delta a se internacionalizar, a visão baseada na Instituição foi um dos parâmetros principais para a escolha do país no qual a filial seria instalada. As opções para ter um IDE eram a América do Sul e Estados Unidos. A primeira, pela relação de proximidade cultural, segundo seu atual CEO. Em relação à segunda opção, foi cogitada pelo tamanho do mercado cervejeiro.

$\mathrm{Na}$ análise do mercado americano, o ex-CFO chegou a visitar o principal cliente americano da Metalúrgica Delta para avaliar a participação numa das concorrências anuais que este cliente faz. Segundo o executivo as condições para participar do processo eram superiores ao que a empresa poderia dar naquele momento, pois, dentre outros pontos, exigiam a instalação de uma unidade fabril ao lado do site do cliente com produção just in time, sendo a Metalúrgica Delta responsável pelo setup das máquinas, por qualquer atraso na linha, problemas de qualidade, atrasos na entrega, além de ser exigido o investimento em máquinas com a mais alta tecnologia disponível no mercado. Diante do cenário, a equipe de gestão da Metalúrgica Delta percebeu que, afora as enormes diferenças psicoculturais e as barreiras governamentais, as empresas estrangeiras, o padrão institucional americano de investimento, tecnológico e de gestão envolvido 
naquela empreitada estavam fora da realidade da empresa e, por isso, ratificaram a decisão de investir num mercado no qual pudessem ser competitivos e tivessem mais proximidade cultural.

Para execução da análise da localidade mais adequada, levantou-se os volumes de exportação na América do Sul, no ano de 2003. Do total exportado, a Argentina representava 69\%, seguida pelo Paraguai, com 23\%, segundo o ex-CFO. Constatou-se, assim, que a Argentina ocupava com larga vantagem a primeira posição na America Latina. No entanto, esse país, no decorrer de sua história, passou por vários colapsos caracterizados pela incerteza institucional (PENG, 2009), e, em 2002, a inadimplência do governo em relação a sua dívida pública ocasionou uma grave crise econômica e financeira.

Em maio de 2003, Néstor Kirchner foi eleito o novo presidente da Argentina e começou a fazer uma série de reformas com o objetivo de estabilizar a economia e tirar o país do cenário de recessão. Em meados de 2004, o momento econômico na Argentina já se mostrava muito melhor, a economia voltava a crescer e a desenhar cenários semelhantes aos do período de pré-recessão (DI BIASI, 2011).

A estabilização do cenário político e econômico, associado à constante demanda de clientes argentinos pela abertura de uma filial naquela localidade, segundo o CEO, foram a alavanca necessária para a escolha do país.

Para minimizar o risco país, a empresa decidiu encontrar um parceiro local na Argentina e, assim, ter acesso facilitado ao conhecimento de leis, de normas técnicas e/ou da cultura local. A empresa parceira na Argentina foi denominada, nesta pesquisa, como Argentina Embalagens. Ela estava presente no mercado desde 1951 e, à época, produzia embalagens e tampas plásticas. Segundo o CEO da empresa, a empresa argentina via na Metalúrgica Delta uma oportunidade de entrar no Brasil. A parceria da Metalúrgica Delta com a Argentina Embalagens atendia, ao mesmo tempo, a dois objetivos da empresa brasileira: abrir a subsidiária na Argentina e associar-se com uma empresa experiente em embalagens plásticas, o que poderia ser uma alternativa para a diversificação de produtos.

\subsubsection{Visão Baseada em Recursos da Firma}

Na visão dos gestores da empresa, a Metalúrgica Delta possuía três grandes vantagens competitivas em seu negócio baseadas em recursos e/ou capacidades internas. A primeira vantagem referia-se ao aspecto tecnológico. Na década de 2000, segundo seu atual CEO, a Metalúrgica Delta tinha uma das linhas de produção de rolhas mais modernas do mundo, perdendo apenas para empresas norte-americanas. Sendo assim, para que pudesse perder esta vantagem competitiva, seriam necessários investimentos vultosos por parte de entrantes e/ou concorrentes.

A segunda grande vantagem competitiva da empresa estava pautada em seu capital humano. A principal linha produtiva deste tipo de segmento é chamada de litografia. Essa linha, para ser operada, exige um altíssimo grau de especialização, dado o seu nível tecnológico e o grau de qualidade exigido por seus clientes. Não existe mão-de-obra com esse tipo de conhecimento disponível no mercado, pois este é oligopolista, dominado por duas empresas que possuem áreas de atuação distintas. Sendo assim, a Metalúrgica Delta formou especialistas internamente e investiu em treinamentos e reciclagens tempestivas de seus profissionais, levando-os para cursos no estrangeiro ou trazendo profissionais internacionais para treiná-los.

A terceira vantagem competitiva era a tradição de mais de 30 anos da empresa, bem como a experiência de seu fundador neste tipo de negócio. Essa vantagem decorre de atributos com características causalmente ambíguas (REED; DEFILLIPPI, 1990), isto é, não existe, por parte dos concorrentes, a compreensão clara e objetiva em relação as ligações entre as ações estabelecidas por meio dos atributos e a vantagem competitiva obtida pela empresa. Sendo assim 
em 2001, quando o patriarca da família faleceu, ocorreu uma quebra no processo de gestão, e a empresa passou por um traumático processo de sucessão.

A Metalúrgica Delta, apesar de possuir recursos e competências difíceis de imitar, por serem valiosos e raros (BARNEY; HESTERLY, 2011; PENG, 2009), viu duas de suas vantagens competitivas - ativo tecnológico e capital humano - serem vencidas pelo poderio de fogo de um de seus maiores clientes. Com a verticalização da AmBev, esses recursos ficaram num elevado nível de ociosidade, ocasionando a busca de novos mercados por parte da Metalúrgica Delta.

\subsection{Falhas no Processo de Internacionalização}

Com a pressão de preços do lado de fornecedores e clientes, com a perda do maior cliente, com o elevado nível de ociosidade e com a melhora do risco país da Argentina, a Metalúrgica Delta decidiu dar vazão ao seu projeto de internacionalização. Após o contato inicial com a Argentina Embalagens em 2004, as empresas iniciaram as tratativas para alinhamento de objetivos e formalização da operação.

A primeira ação da Metalúrgica Delta foi enviar uma linha de produção que estava parada no Brasil para a joint venture formada na Argentina (Metalúrgica Delta Argentina). A linha enviada era a que fazia a etapa de corte das tampas metálicas e aplicação do vedante. No entanto o coração deste tipo de negócio é a litografia. Sendo assim, a estratégia adotada foi de enviar as folhas já impressas do Brasil para a Argentina, através de frete marítimo. Com isso, a etapa que mais agregava valor ao processo permaneceria no Brasil.

Após a definição de como seria o processo produtivo, a divisão de responsabilidades entre os sócios ficou: Metalúrgica Delta produzia e enviava as folhas impressas para a Argentina Metalúrgica Delta, e a Argentina Embalagens cuidaria do processo de corte, venda e gestão local.

Em outubro de 2004, no primeiro envio de folhas impressas, ocorreu o primeiro problema. A Administração Federal de Ingressos Públicos (AFIP) ou Receita Federal da Argentina não liberou a entrada das folhas impressas. Nesse momento, foram descobertos outros pontos não levados em consideração no planejamento inicial da operação: (i) segundo o atual CEO da empresa, as instituições públicas argentinas são extremamente burocráticas e pouco informatizadas; (ii) conforme o ex-controller da empresa, a folha litografada é considerada produto semiacabado na Argentina e como medida de proteção à atividade local, é sobretaxada.

Os dois pontos mencionados apresentaram-se como falhas mortais ao planejamento inicial. No caso do primeiro ponto, porque o tempo da mercadoria parada na Alfândega Argentina comprometeu de forma muito prejudicial os prazos acordados com os clientes, causando o desabastecimento destes, fato que raramente ocorria quando das exportações.

O caso da tributação é fato ainda mais grave. A Lei que rege o imposto sobre mercadorias na Argentina (IVA) dá direito ao crédito dos impostos pagos na aquisição de mercadorias, quando da apuração dos débitos por venda. O ponto é que, com a sobretaxa fiscal, o valor do crédito do imposto mantinha-se em patamares muito elevados.

A operação começou a funcionar, e uma série de outras lacunas apareceram. A primeira é relativa ao envio das folhas litografadas para a Argentina. O modelo operacional de envio de folhas litografadas não poderia ser efetivado para pequenas quantidades, pois, para consolidar contêineres, havia uma quantidade mínima de envio. Esse fato, além do tempo já gasto para liberação das mercadorias na Alfândega Argentina, onerava ainda mais o lead time de atendimento dos clientes, tendo em vista que, em várias situações, os clientes tinham que esperar fechar a quantidade dos contêineres para serem atendidos. Referente a esse mesmo item, ainda havia de se considerar o tempo em viagem das rolhas, que demoravam de 7 a 10 dias para chegar à Argentina. 
Após as primeiras vendas, verificou-se que os débitos de IVA na venda eram inferiores aos créditos pela compra das folhas litografadas. Então a Metalúrgica Delta Argentina envidou esforços, sem sucesso, no sentido de tentar reajustar os valores dos preços de vendas aos clientes locais.

Devido aos vários problemas de desabastecimento e atrasos, a operação não apresentou constância, como se pode observar no Quadro 2, que trata do envio de chapas litografadas para a filial Argentina.

Quadro 2 - Envio de folhas litografadas para a Argentina
\begin{tabular}{|cr|}
\hline Mês & Valor Envio $\mathbf{R} \mathbf{\$}$ \\
\hline out/04 & $63.561,74$ \\
dez/04 & $51.894,00$ \\
ago/05 & $9.023,20$ \\
out/05 & $145.432,00$ \\
nov/05 & $170.095,00$ \\
dez/05 & $262.173,00$ \\
jan/06 & $227.146,00$ \\
mar/06 & $187.980,00$ \\
mai/06 & $98.980,00$ \\
\hline Total geral & $\mathbf{1 . 2 1 6 . 2 8 4 , 9 4}$ \\
\hline
\end{tabular}

Fonte: Metalúrgica Delta.

Com isso, o modelo adotado não se rentabilizou. Em 2006, com a mudança de gestão financeira da Metalúrgica Delta, foi calculada a estimativa de perdas da operação, e chegou-se aos seguintes valores (expressos em R\$ mil), que podem ser vistos no Gráfico 1.

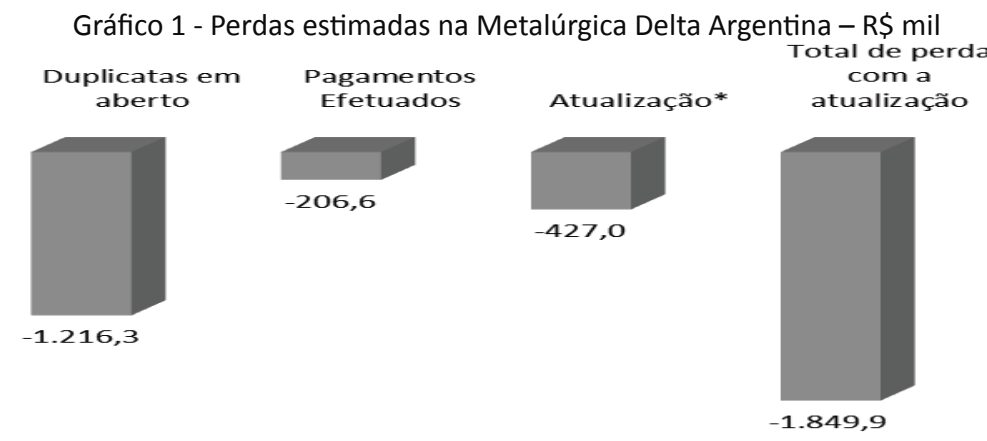

Fonte: Metalúrgica Delta.

Dado a todos esses entraves no modelo desenhado, bem como os resultados que não rentabilizavam a operação, a gestão da Metalúrgica Delta resolveu por descontinuar a operação na Argentina em 2006. Segundo o atual CEO, devido à extrema burocracia no país, a previsão para completo encerramento da Metalúrgica Delta Argentina perante todos os órgãos cabíveis era em dezembro/2013.

\subsection{Discussão dos Resultados}

A internacionalização da Metalúrgica Delta ocorreu por vários fatores. Em síntese, a dependência do mercado brasileiro de bebidas acarretou uma pressão exacerbada para redução de preços ao longo da década passada. Para Prezzotto e Lavall (2010), uma forte característica deste mercado é a concentração da demanda por produtos nas mãos de poucos clientes, que ocasionou uma ação conjunta e organizada do segmento sob a empresa analisada. 
Por outro lado, a dependência de seu único fornecedor no Brasil ensejava em pressão contínua o aumento de custo. Para Pontes (2009), quanto menor for a relevância dos clientes para os fornecedores e maiores forem os custos de mudança de fornecedor, maior será o potencial de impacto negativo no desempenho. No caso da Metalúrgica Delta, foi exatamente isso o que aconteceu.

Em adição, ainda pode-se mencionar a verticalização ocorrida na AmBev, que figurava como maior cliente da Metalúrgica Delta, ocasionando relevante ociosidade no parque fabril desta. Esses três fatores associados levaram a empresa a apresentar contínuos prejuízos e aumento do endividamento.

A internacionalização da Metalúrgica Delta representava a chance de sustentabilidade e crescimento da empresa, tanto financeiramente como em termos de eficiência e organização; caso contrário, passaria por sérios problemas de continuidade no contexto do mercado nacional. As motivações de internacionalização da Metalúrgica Delta corroboram o anteriormente mencionado por Pereira (2012) e por Dunning e Lundan (2008) em seus estudos, no que se refere ao acesso a mercados e à eficiência de ativos.

Contudo a empresa analisada apresentou algumas falhas vitais em seu processo de internacionalização. Primeiramente, devido à falta de executivos experientes na atuação com mercados internacionais. Conforme alertado por Engelman e Fracasso (2013), para uma empresa se internacionalizar, é imprescindível que os executivos tenham experiência no mercado internacional. Corroborando essa idéia, tanto Nummela, Saarenketo e Loane (2016) quanto Ooghe e De Prijcker (2008) citam que a falta de capacidade dos administradores para lidar com as responsabilidades adicionais encontradas ao entrar em mercados internacionais é um dos principais motivos de fracasso nesse tipo de empreitada. No caso em estudo, por tratar-se de uma empresa familiar e pouco profissionalizada à época, sua administração carecia de visão global e experiência internacional, além de ter tido enorme dificuldade de lidar com as novas rotinas e os novos desafios associados ao processo de gerir uma sucursal no estrangeiro. Casillas (2012) menciona que uma empreitada no mercado internacional deve decorrer de mudanças internas na mente dos administradores de uma empresa e em sua cultura e/ou rotinas organizacionais, fato este que não ficou evidenciado na Metalúrgica Delta.

Um outro ponto que impactou no insucesso da Metalúrgica Delta foi a falta de conhecimento detalhado do mercado alvo de atuação, no caso a Argentina, bem como de suas leis, estando estes dois aspectos em linha com o mencionado por Wang (2010) e Carvalho (2013). Primeiramente, pode-se mencionar as características das instituições governamentais argentinas, a alta tributação na importação de matéria prima e a extrema burocracia nos órgãos públicos. A elevada tributação afetou significativamente os lucros da empresa e, caso esta tivesse avaliado o mercado de forma mais profunda e o compreendido, talvez tivesse chegado à conclusão de que aquele mercado não era propício ao modelo de negócio que se intentava implantar. Essa falta de entendimento fez com que a empresa gastasse uma enorme quantidade de recursos, dentre eles dinheiro, capital humano e tempo, num negócio que já nasceu fadado ao insucesso, estando também esse desentendimento em linha com os fatores de insucesso mencionados por Lu, Tao e Chan (2008) em sua pesquisa.

Outra debilidade emergiu do processo de internacionalização propriamente dito, dada a falta de reestruturação empresarial da empresa-mãe para administração da sucursal, uma vez que esta não criou estrutura interna para o acompanhamento e o controle das atividades internacionais. Dessa forma, apresentou uma profunda dificuldade em perceber a real evolução operacional e financeira de sua sucursal, corroborando o mencionado por Engelman e Fracasso (2013).

Por fim, os administradores da empresa constataram que o esforço realizado para a implementação de uma sucursal era elevado, tanto ao nível financeiro e administrativo, quanto ao pessoal, e que a experiência colocou em xeque os ganhos da internalização. Os obstáculos 
encontrados acarretaram sucessivos resultados negativos. Nummela, Saarenketo e Loane (2016) mencionaram que as consequências do fracasso em processos de internacionalização podem findar no completo encerramento do negócio. Esse foi o caso da Metalúrgica Delta.

Percebeu-se, assim, que a escolha da localidade pela Metalúrgica Beta se pautou somente no quesito estabilidade política e econômica. Questões como o preparo de seus executivos, a burocratização das instituições argentinas, bem como as legislações fiscal e tributária aplicáveis ao negócio, deixaram de ser averiguadas. Isso levou a estratégia de internacionalização da empresa ao insucesso.

\section{CONSIDERAÇÕES FINAIS}

As perguntas que se buscou responder com a presente pesquisa foram: "Em qual contexto se deu a internacionalização da Metalúrgica Delta?"; e "Que fatores levaram a empresa a não obter êxito nesta estratégia?". Para responder a esses questionamentos, foi necessário atender a dois objetivos propostos no estudo, sendo eles: (i) investigar como se deu o processo de internacionalização da empresa Metalúrgica Delta, amparada na visão mercado x RBV $\mathrm{x}$ instituição; e (ii) Descrever que fatores impactaram no insucesso da empreitada.

Com base no referencial teórico utilizado, bem como por meio de entrevistas com alguns dos administradores da empresa à época da internacionalização e da obtenção de alguns dados de resultado do negócio, foi possível chegar a algumas conclusões.

Primeiramente, no que se refere ao contexto da internacionalização, foi observado que a análise efetuada pelos administradores da empresa no cenário de pré-internacionalização, a força cliente e os fornecedores atuaram como importantes indutores do processo, principalmente devido à transição de seu fornecedor da iniciativa pública para a privada. Além disso, após vivenciar uma forte crise sob o prisma dos clientes, forças de Porter (1990), com a fusão da Ambev, houve uma intensa necessidade de escoar sua capacidade produtiva para outro mercado, e a internacionalização surgiu como alternativa natural.

Sob o enfoque da RBV, o excesso de confiança dos administradores da empresa em vantagens competitivas, baseadas em recursos e competências, fez com que não fosse efetuada uma análise mais aprofundada do mercado alvo da internacionalização. Constatou-se também que os recursos e as competências relacionados pela empresa não se configuraram como vantagens competitivas para a sucursal na Argentina, pois eram pontos fortes no mercado brasileiro, sob a condicionante desta localidade e modelo de negócio.

No que se refere à visão baseada nas instituições, pode-se constatar que a análise da localidade pautou-se unicamente no risco país, sem que fosse adensada a análise de questões legais e fiscais, a burocratização das instituições ou os aspectos de mercado protecionistas do país.

Em relação ao segundo objetivo específico da pesquisa, verificou-se, por meio dos dados coletados nas entrevistas e nos documentos, que os grandes causadores do insucesso da estratégia de internacionalização da empresa foram a falta de experiência dos gestores em negócios globais e, por consequência, o limitado poder de reação frente às dificuldades encontradas. Outro fator foi a ausência de um plano estratégico que vislumbrasse, dentre outros aspectos, as questões institucionais da Argentina, e que não pautasse a análise unicamente na vertente do risco país.

Assim, por meio dos resultados apresentados, pode-se constatar que os objetivos estabelecidos para o estudo foram atendidos.

Por fim, a presente pesquisa tentou contribuir no preenchimento da lacuna citada por Nummela, Saarenketo e Loane (2014), no que se refere à necessidade de ir além da análise do processo de fracasso e entender o contexto vivenciado pela empresa, bem como as consequências do insucesso. 
Sob o prisma gerencial, com base nos achados de pesquisa, a sugestão deste estudo é que, em processos de expansão internacional, os administradores das empresas efetuem uma análise profunda sob a ótica do Tripé Estratégico (mercado x RBV x instituições), sem desconsiderar ou subavaliar nenhuma dessas dimensões, dado que a análise inadequada de único fator pode colocar em risco o projeto como um todo. Importante ressaltar o papel do capital humano e o das instituições, visto que o primeiro tende a garantir a capacidade de gestão e a de reação; e o segundo tende a conhecer os aspectos legais, burocráticos e protecionistas do país em que se pretende atuar.

Apesar dos resultados relevantes para o entendimento do processo de internacionalização e de suas falhas, este estudo possui suas limitações. Por se tratar de um estudo de caso, não há como generalizar os achados, uma vez que pode ser específico da empresa, do setor ou mesmo das características do país hospedeiro.

Ao analisar a internacionalização, deve ser considerado que ampliar horizontes das empresas leva à revisão de conceitos e à concentração de maiores esforços em processos decisórios, principalmente naqueles que envolvem as estratégias adotadas e a escolha de países em que a inserção da empresa será efetivada. Assim, em estudos futuros, sugere-se: (i) analisar outros processos de insucessos de internacionalização, envolvendo um número maior de empresas, diferentes setores ou países hospedeiros para verificar a aplicabilidade dos resultados obtidos nesta pesquisa; (ii) avaliar o impacto da experiência da alta gestão na performance e na continuidade de processos de internacionalização; e (iii) avaliar o percentual de multinacionais instaladas na Argentina que encerraram suas atividades após curto espaço de tempo e a influência das instituições nesse processo.

\section{REFERENCIAS}

BARDIN, L. Análise de Conteúdo. São Paulo: Edições 70, 2012.

BARNEY, J. B. Firm resources and sustained competitive advantage. Journal of Management, Thousand Oaks, v. 17, n. 1, p. 99-120, 1991.

BARNEY, J. B.; HESTERLY, W. S. Administração Estratégica e Vantagem Competitiva. São Paulo: Pearson, 2011.

BIRKINSHAW, J.; FRY, N. Subsidiary initiatives to develop new markets. Sloan Management Review, Massachusetts, v. 39, n. 3, p. 51-61, 1998.

BUCKLEY, P. J.; CASSON, M. C. The internalisation theory of the multinational enterprise: A review of the progress of a research agenda after 30 years. Journal of International Business Studies, Basingstoke, v. 40, n.9 p. 1563-1580, 2009.

CARDON, M.; STEVENS, C.; POTTER, , D.R. Misfortunes or mistakes? Cultural sensemaking of entrepreneurial failure. Journal of Business Venturing, New York, v. 26, n. 1, p. 79-92, 2011.

CARTER, S.; WILTON, W. Don't blame the entrepreneur, blame the government: The centrality of the government in enterprise development; lessons from enterprise failure in Zimbabwe. Journal of Enterprising Culture, Singapore., v. 14, n. 1, p. 65-84, 2006.

CARVALHO, M. A. Internacionalização empresarial portuguesa no Brasil sobre a forma de IDE: estudo de caso ALERT, Águas de Portugal e SORUS. 2013. 192 f. Dissertação (Mestrado em Negócios Internacionais)-Universidade do Minho, Minho, 2013. 
CASILLAS, J C.; ACEDO, F. J. Speed in the Internationalization Process of the Firm. International Journal Of Management Reviews, [s.l.], v. 15, n. 1, p. 15-29, 28 fev. 2012. Disponível em: <http:// api.wiley.com/onlinelibrary/tdm/v1/articles/10.1111/j.1468-2370.2012.00331.x>. Acesso em: 05 mar. 2016.

CHEN, H.; HSU, W.; CHANG, C. Family Ownership, Institutional Ownership, and Internationalization of SMEs. Journal Of Small Business Management, [s.I.], v. 52, n. 4, p. 771-789, 19 ago. 2013. - Disponível em: <http://api.wiley.com/onlinelibrary/tdm/v1/articles/10.1111/jsbm.12031>. Acesso em: 06 mar. 2016.

COAD, A. Death is not a success: Reflections on business exit. International Small Business Journal, Thousand Oaks, v.32, n. 7, p. 721-732, 2014.

DI BIASE, F. R. Argentina: Da Crise ao Sucesso. Disponível em: <http://www.globalresearch.ca/ argentina-da-crise-ao-sucesso>. Acesso em: 14 nov. 2013.

DUNNING, J. H.; LUNDAN, S. M. Institutions and the OLI paradigm of the multinational enterprise. Asia Pacific Journal of Management, New York, v. 25, n. 4, p. 573-593, 2008.

The institutional origins of capabilities in multinational enterprises. Industrial and Corporate Change, Oxford, v. 19, n. 4, p. 1225-1246, 2010.

ENGELMAN, R.; FRACASSO, E. M. Contribuição das incubadoras tecnológicas na internacionalização das empresas incubadas. Revista de Administração da Universidade de São Paulo-RAUSP, São Paulo, v. 48, n. 1, p. 165-178, 2013.

FABRY, N.; ZEGHNI, S. Inward FDI in seven transitional countries of South-Eastern Europe: a quest of institution-based attractiveness. Eastern Journal of European Studies, Romania, v. 1, n. 2, p. 77-91, 2010.

GALBREATH, J.; GALVIN P. Firm Factors, Industry Structure and Performance Variation: New Empirical Evidence to a Classic Debate. Journal of Business Research, Netherlands, v. 61, n.2, p. 109-117, 2008.

HELFAT, C. et al. Dynamic capabilities and organizational processes. IN: HELFAT, C. E.; FINKELSTEIN, S.; MITCHELL, W.; PETERAF, M.; SINGH, H.; TEECE, D.; WINTER, S. (Ed.). Dynamic Capabilities: Understanding Strategic Change in Organizations. London: Blackwell, 2007. p. 30-45.

HENNART, J-F. A transaction costs theory of equity joint ventures. Strategic Management Journal, New Jersey, v. 9, n. 4, p. 361-374, 1988.

HOSKISSON, R. E. et al. Estratégia Competitiva. 2a. ed. São Paulo: Cengage Learning, 2009.

IRELAND, R. D.; HOSKISSON, R. E.; HITT, M. A. Understanding Business Strategy: Concepts and Cases. 3rd. ed. OH, USA: South-Western, Cengage Learning, 2009.

JOHANSON, J.; VAHLNE, J. E. The Uppsala internationalization process model revisited - From liability of foreignness to liability of outsidership. Journal of International Business Studies, Basingstoke, v. 40, n. 9, p. 1411-1431, 2009.

JOHANSON, J.; WIEDERSHEIM-PAUL, F. The internationalization of the firm: Four Swedish cases. Journal of Management Studies, Massachusetts, v. 12, n. 3, p. 305-322, 1975. 
KISS, A.; DANIS, W. Country institutional context, social networks, and new venture internationalization speed. European Management Journal, New York, v. 26, n. 6, p. 388-399, 2008.

LU, J.; TAO, Z.; CHAN, I. eBay's Strategy in China: Alliance or Acquisition. Hong Kong: Asia Case Research Centre, Asia Case Research Centre: The University of Hong Kong, 2008.

MERRIAM, S. B. Qualitative research and case study applications in education. San Francisco: Jossey-Bass, 1998.

MONTICELLI, J.M.; VASCONCELLOS, S.L.; GARRIDO, I.L. Political perspectives of relationship networks to internationalization of firms in an emerging economy. Internext, v.12, n.2, p.74-89, 2017. http://dx.doi.org/10.18568/1980-4865.12274-89

NORTH, D. C. Institutions, institutional change and economic performance. Cambridge: Cambridge University Press, 1990.

NUMMELA, N.; SAARENKETO, S.; LOANE, S. The dynamics of failure in international new ventures: A case study of Finnish and Irish software companies. International Small Business Journal: Researching Entrepreneurship, [s.l.], v. 34, n. 1, p.51-69, 11 jul. 2016. http://dx.doi. org/10.1177/0266242614539363

OOGHE, H.; DE PRIJCKER, S., Failure processes and causes of company bankruptcy: A typology. Management Decision, Bingley, v. 46, n. 2, p. 223-242, 2008.

PENG, M. W. Global Strategy. Mason: Cengage Learning, 2009.

PENG, M.; WANG, D.; JIANG, Y. An institution-based view of international business strategy: a focus on emerging economies. Journal of International Business Studies, Basingstoke, v. 39, n. 5, p. 920-936, 2008.

PEREIRA, L. H. Internacionalização: quem vai encarar? Gv Executivo, São Paulo, v. 11, n. 1, p. 5657, jun. 2012.

PONTES, Leandro Cangussú Reis. Análise da estratégia do setor supermercadista do Estado do Pará: Uma aplicação do modelo de cinco forças competitivas de Michael Porter. 2009. 138 f. Dissertação (Mestrado em Economia)-Universidade Federal do Pará, Belém, 2009.

PORTER, M. E. Competitive strategy: Techniques for analyzing industries and competitors. New York: The Free Press, 1980.

. Estratégia Competitiva - Técnicas para análise de indústrias e da concorrência. 18a. ed. São Paulo-SP: Campus, 1986.

. The Competitive Advantage of Nations. New York: Free Press, MacMillan, 1990.

. Estratégia competitiva: técnicas para análise e da concorrência. 17. ed. Rio de Janeiro: Elsevier, 1999.

PRANGE, C.; VERDIER, S. Dynamic capabilities, internationalization processes and performance. Journal of World Business, New York, v. 46, n. 1, p. 126-133, 2011.

PREZZOTTO, K.; LAVALL, V. L. AMBEV - Análise da fusão e os efeitos sobre o mercado. 
Disponível em: < http://www.apec.unesc.net/V_EEC/sessoes_tematicas/Economia\%20 industrial,\%20ci\%C3\%AAncia,\%20tecnologia\%20e\%20inova\%C3\%A7\%C3\%A3o/AMBEV\%20 \%20AN\%C3\%81LISE\%20DA\%20FUS\%C3\%830\%20E\%20OS\%20EFEITOS\%20SOBRE\%200\%20 MERCADO.pdf>. Acesso em: 16 nov. 2013.

REED, R.; DEFILLIPPI, R. J. Causal Ambiguity, Barriers to Imitation, and Sustainable Competitive Advantage. Academy of Management Review, New York, v. I., n. 15, p. 88-102, 1990.

REIN, S. EBay's Tom Online Deal: Timely Lessons for Global Online Company Managers. 2007. Disponível em: <https://seekingalpha.com/article/27041-ebays-tom-online-deal-timely-lessonsfor-global-online-company-managers $>$. Acesso em: 07 jun. 2018..

SHARMA, D.; BLOMSTERMO, A. The internationalization process of born globals: a network view. International Business Review, New York, v. 12, p. 739-753, 2003.

SLACK, N.; CHAMBERS, S.; JOHNSTON, R. Administração da produção. 3. ed. São Paulo: Atlas, 2009.

SLEUWAEGEN, L.; ONKELINX, J. International commitment, post-entry growth and survival of international new ventures. Journal of Business Venturing, New York, v. 29, n. 1, p. 106-120, 2014.

SOUSA FILHO, J.M.; BARBIERI, J.C. Estratégia socioambiental baseada em recursos e ambiguidade causal. Revista de Administração de Empresas - RAE, v.55, n.6, p.699-711, 2015.

VASCONCELLOS, E. Internacionalização, estratégia e estrutura: o que podemos aprender com o sucesso da Alpargatas, Azaleia, Fanem, Voith e Volkswagen. São Paulo: Atlas, 2008.

VIEIRA, M. M. F.; ZOUAIN, D. M. (Org.). Pesquisa Qualitativa em Administração. 2. ed. Rio de Janeiro: FGV, 2006.

WANG, H. H. How EBay Failed In China. Forbes, New Jersey, p. 1-2. 12 set. 2010. Disponível em: <https://www.forbes.com/sites/china/2010/09/12/how-ebay-failed-in-china/\#11b777835d57>. Acesso em: 07 jun. 2018.

WILLIAMSON, O. E. Transaction cost economics and business administration. Scandinavian Journal of Management, New York, v. 21, p. 19-40, 2005.

XAVIER, A. N.; TUROLLA, F. A Internacionalização da Empresa Brasileira: a Literatura e Alguns Fatos Estilizados. In: CICLO DE DEBATES EITT, GRUPO DE ESTUDOS EM ECONOMIA INDUSTRIAL, 4., 2006, São Paulo. Anais... São Paulo: PUCSP, 2006. p. 1-14. 